\title{
Erratum to: Blood glucose concentration profile after single dose of dexamethasone during operation in dogs
}

\author{
Hamidreza Fattahian • Hamidreza Moosavian • \\ Hamid Mohyeddin • Hesameddin Akbarein • \\ Roozbeh Moridpour
}

Published online: 24 January 2013

(C) Springer-Verlag London 2013

Erratum to: Comp Clin Pathol (2012) 21:957-960

DOI 10.1007/s00580-012-1594-3

The original version of this article inadvertently contained a mistake. The correct name of the fourth author is Hesameddin Akbarein.

The online version of the original article can be found at http:// dx.doi.org/10.1007/s00580-012-1594-3.

H. Fattahian $(\bowtie) \cdot R$. Moridpour

Department of Surgery, Faculty of Specialized Veterinary

Sciences, Science and Research Branch, Islamic Azad University,

Tehran, Iran

e-mail: hrfattahian@yahoo.com

H. Moosavian

Department of Clinical Sciences, Faculty of Veterinary Medicine,

University of Tehran, Tehran, Iran

H. Mohyeddin

Department of Clinical Sciences, Faculty of Veterinary Medicine,

Garmsar Branch, Islamic Azad University, Garmsar, Iran

H. Akbarein

Department of Food Hygiene, Division of Epidemiology and Zoonoses, Faculty of Veterinary Medicine,

University of Tehran, Tehran, Iran 